\title{
Effect of Fiber Loading on the Mechanical Properties of Jute Fiber Reinforced Polypropylene Composites
}

\section{Subrata Chandra Das ${ }^{1,2 *}$, Debasree Paul2,3, Mir Muhammad Fahad4, Mithun Kumer Das5, G. M. Shafiur Rahman', Mubarak Ahmad Khan²}

\footnotetext{
${ }^{1}$ Bangabandhu Textile Engineering College, Department of Textiles, Ministry of Textiles and Jute, Tangail, Bangladesh ${ }^{2}$ Institution of Radiation and Polymer Technology, Atomic Energy Research Establishment, Bangladesh Atomic Energy Commission, Dhaka, Bangladesh

${ }^{3}$ Department of Textile Engineering, Khwaja Yunus Ali University, Sirajgonj, Bangladesh ${ }^{4}$ Department of Research and Development, Echo Sourcing (Pvt.) Ltd., Gazipur, Bangladesh ${ }^{5}$ Department of Textile Engineering, Daffodil International University, Dhaka, Bangladesh ${ }^{6}$ Department of Materials Science and Engineering, University of Rajshahi, Rajshahi, Bangladesh Email: *sc.das_mbstu@yahoo.com
}

How to cite this paper: Das, S.C., Paul, D. Fahad, M.M., Das, M.K., Shafiur Rahman, G.M. and Khan, M.A. (2018) Effect of Fiber Loading on the Mechanical Properties of Jute Fiber Reinforced Polypropylene Composites. Advances in Chemical Engineering and Science, 8, 215-224.

https://doi.org/10.4236/aces.2018.84015

Received: August 1, 2018

Accepted: September 17, 2018

Published: September 20, 2018

Copyright $\odot 2018$ by authors and Scientific Research Publishing Inc. This work is licensed under the Creative Commons Attribution International License (CC BY 4.0).

http://creativecommons.org/licenses/by/4.0/

\section{(c) (i) Open Access}

\begin{abstract}
Jute fiber (woven fabric, $1 \times 1$ plain weave) reinforced polypropylene matrix composites were prepared by compression molding with various fiber loading such as $30 \%, 40 \%, 46 \%, 50 \%, 55 \%$ by weight. The mechanical properties such as tensile strength (TS), bending strength (BS), tensile modulus (TM), bending modulus (BM) and impact strength (IS) of the composite were assessed and analyzed. The highest value of TS, BS, TM, BM and IS were $68.1 \mathrm{MPa}$, 94.1 MPa, $2936 \mathrm{MPa}, 4831 \mathrm{MPa}$ and $14.5 \mathrm{~kJ} / \mathrm{m}^{2}$ respectively with $50 \%$ fiber loading by weight. It was found that the mechanical properties of the composites were increased with the increase in jute fiber content up to $50 \%$ by weight; however, further increase in fiber loading the value decreased. On the basis of fiber content, 50\% fiber reinforced composites had the optimum set of mechanical properties. Initially the water absorption rate was higher and then it became slower and static with time. Chemical ageing test with various chemical media such as $\mathrm{H}_{2} \mathrm{O}_{2}, \mathrm{NaOH}, \mathrm{HCl}$ and $\mathrm{NaCl}$ were performed up to 168 hours. After first 24 hours the composite samples showed gradual weight gain (\%) and then the weight gain was become slow and steady in the chemical solution.
\end{abstract}

\section{Keywords}

Fiber Loading, Jute Fiber, Polypropylene, Chemical Ageing, Tensile Properties 


\section{Introduction}

Fiber reinforced polymer matrix composites are versatile in applications with excellent physico-mechanical properties. They are widely used in various applications such as furniture, building materials, automotive industry, civil and military, biomedical and many other applications. Among various natural and synthetic fibers, the demand of natural fibers like jute, hemp, sisal, flax, coir, pineapple etc. are increasing day by day due to their ecofriendly nature and availability in the market [1] [2] [3] [4] [5]. Jute is a dominant natural bast fiber in the world market which is mostly produced in Bangladesh and India. The jute fiber has some promising properties like long staple length, excellent tensile properties, low density, nonabrasive nature, low price and very easy to processing. It is a lignocellulosic fiber and main constituents are $\alpha$-cellulose, hemicelluloses and lignin [2] [4] [6] [7]. Jute is extensively used in the production of ropes, sacks, packaging, carpet backings, furnishing fabrics, geotextiles materials and composite materials etc. [8] [9] [10].

Polypropylene (PP) is an amorphous polymer and is extensively used as an engineering thermoplastic due to its various important and convenient features like clarity, dimensional firmness, anti-flame properties, high heat distortion temperature and high impact strength. It can be applicable for filling, reinforcing and blending. The incorporation of PP with natural fibers can be an auspicious way to develop natural-synthetic polymer composites [11] [12] [13]. The tensile behavior of jute-PP composite were found with fiber volume percentage of $20 \%$ - 80\% [14]; woven jute fabric-PP commingled composite were studied by Souza et al. [15] and the effectiveness of coupling agents on the mechanical properties of jute/PP composites reported by Khan et al. [16]. Ramli et al. [17] studied the consequences of fiber loading, fiber type, its mesh size and coupling agent on the characteristics of oil palm biomass/PP composites. Rahman et al. [18] studied the physico-mechanical characteristics of jute/PP composites. Both raw and oxidized jute fiber was used and four levels of fiber loading were used for composite fabrication such as $20 \%, 25 \%, 30 \%, 35 \%$ by weight. On the basis of fiber loading, $30 \%$ fiber reinforced composite showed the optimum set of mechanical features. Kasim [19] investigated the outcome of pineapple leaf fiber (PALF) loading (30\% - 70\% fiber content) on the mechanical characteristics of PALF/PP composites. The best mechanical properties were found for 30/70 wt\% PALF/PP composite. Rasel et al. [20] reported the effect of coupling agent and fiber loading on mechanical behavior of chopped jute fiber reinforced PP composites. Morri et al. [21] showed the effect of water environment on jute/PP composites. The weight gain by water absorption was significantly affected by the fiber content. The specimens with the jute fiber content of $30 \mathrm{wt} \%$ more easily absorbed water and it reached more than $10 \%$.

The purpose of this study is to fabricate and find out the mechanical properties of jute fabric reinforced PP composites with various fiber loading (weight\%). The water uptake (\%) and the resistance in various chemicals of the composites 
were also analyzed in this work.

\section{Materials and Method}

\subsection{Materials}

Polypropylene (PP) granules were purchased from Polyolefin Company, Singapore. Jute woven fabric (Hessian Cloth, $1 \times 1$ plain weave) was used as reinforcement which was collected from the local market of Dhaka, Bangladesh.

\subsection{Methods}

\subsubsection{Preparation of PP Sheets}

PP sheets were fabricated using granules of PP (about $15 \mathrm{~g}$ ) by placing the granules into two steel plates. The steel plates were then placed into the hot press (Carver, INC, USA, Model 3856). The presses were operated at $180^{\circ} \mathrm{C}$ and 5 tons pressure was applied on steel plates for $5 \mathrm{~min}$. Then it was cooled for $5 \mathrm{~min}$ in a separate press (cold press) under 5 tons pressure at room temperature. Then, the prepared PP sheets were cut into small pieces of desired dimension for composites fabrication.

\subsubsection{Composite Preparation}

Jute/PP composites were fabricated by sandwiching pre-weighed layers of jute fabric between the layers of PP sheets. Composites were prepared by pressing this sandwich at $190^{\circ} \mathrm{C}$ for 5 minutes under a pressure of 5 tons using Carver Laboratory Press (Carver, INC, USA, Model 3856). After heating and pressing, the mold was cooled in a cooling system using another press. In this way, composite of mold size was prepared.

\subsubsection{Mechanical Testing of the Composites}

i) Tensile Test

Tensile tests were performed according to ASTM Designation: D638-03 using a Universal Testing Machine (model: H50KS-0404, Hounsfield Series S, UK) with a cross-head speed of $10 \mathrm{~mm} / \mathrm{min}$ at a span distance of $50 \mathrm{~mm}$. The dimensions of the test samples were $120 \mathrm{~mm} \times 15 \mathrm{~mm}$.

ii) Bending Test

Bending tests were conducted according to ISO 14125 methods using the same testing machine mentioned above with a cross-head speed of $60 \mathrm{~mm} / \mathrm{min}$ at a span distance of $25 \mathrm{~mm}$. The dimensions of the test specimen were $60 \mathrm{~mm} \times 15 \mathrm{~mm}$.

iii) Impact Test

The impact tests were carried out on unnotched mode composite samples according to ASTM D 6110-97 using a Universal Impact Tester (HUNG TA INSTRUMENT CO. LTD., Taiwan), hammer mass of $2.63 \mathrm{~kg}$, gravity distance of $30.68 \mathrm{~mm}$ and lift angle of $150^{\circ}$.

iv) Water Uptake

Composites specimens $\left(20 \times 10 \times 2 \mathrm{~mm}^{2}\right)$ were soaked in a static water bath at $25^{\circ} \mathrm{C}$ for various time periods (up to 168 hours). Before immersion in water, the 
samples were dried in an oven at $105^{\circ} \mathrm{C}$, cooled in a desiccators using silica gel and weighed. After certain periods of time, samples were taken out from the bath and wiped using tissue paper, then weighed. Water uptake was measured by the subtraction from final weight to initial weight.

v) Chemical Ageing Test

Composites samples were immerged in $20 \%$ different types of chemical solution $\left(\mathrm{H}_{2} \mathrm{O}_{2}, \mathrm{NaOH}, \mathrm{HCl}, \mathrm{NaCl}\right)$ up to 168 hours. After certain periods of time, samples were taken out from the bath and wiped using tissue paper, then weighed. Weight gain or loss percentage was determined by the subtraction from final weight to initial weight.

\section{Result and Discussion}

\subsection{Mechanical Properties}

The influence of jute content on the mechanical features of jute/PP composite was measured and the results are showed in Figures 1-3. The TS and BS of the composites were found to increase on increasing the percentage of jute fiber content in the composites. The higher TS and the BS at 50\% jute content were found to be 68.1 and $94.1 \mathrm{MPa}$ respectively. The TM and BM of the composite also followed the same way like TS and BS. The highest TM and BM of the composites were obtained as 2936 and $4831 \mathrm{MPa}$ respectively as shown in Figure 2 .

The maximum values of mechanical properties displayed by $50 \%$ fiber loading composite may be illustrated in terms of orientation and homogeneity of fibers within the matrix. At this stage, jute fibers get highest level of orientation and mixed homogeneously within the matrix. When the load is applied, stress is uniformly distributed among the fibers. As a result, mechanical properties of the composites obtained highest values. At low fiber content, poor fiber population contributes low load transfer capacity among the fibers. As a result, accumulation of stress occurs at certain points of the composite and strains are also found highly localized in the matrix [22] [23]. This contributes poor mechanical properties of the composites at low fiber content. Whereas, at high level of jute contents,

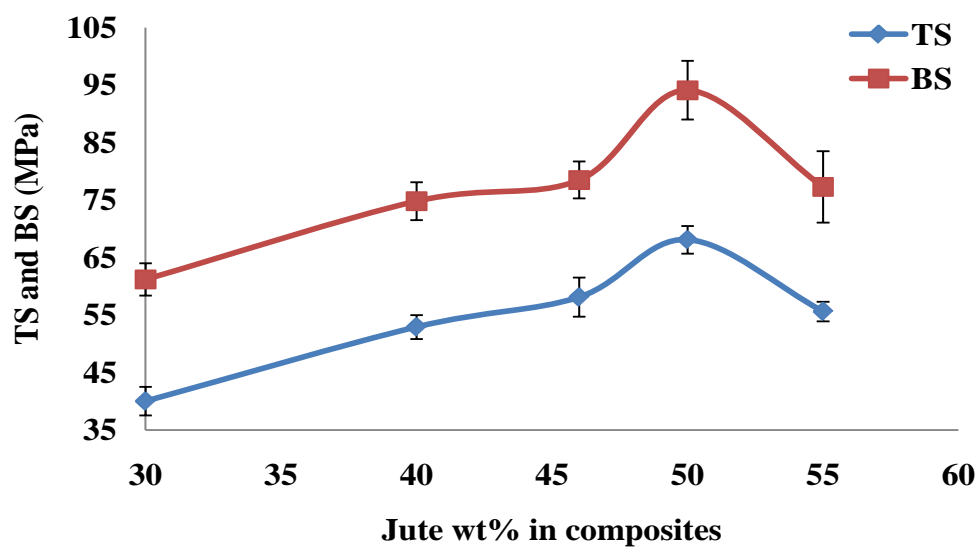

Figure 1. Effect of jute fiber loading (wt $\%$ ) on the TS and BS of jute/PP composites. 


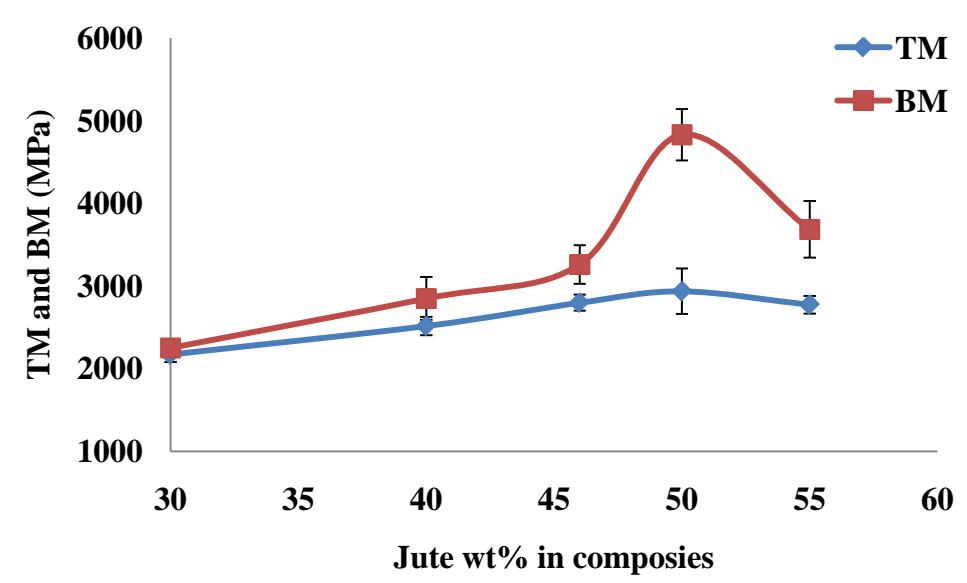

Figure 2. Effect of jute fiber loading (wt\%) on the TM and BM of jute/PP composites.

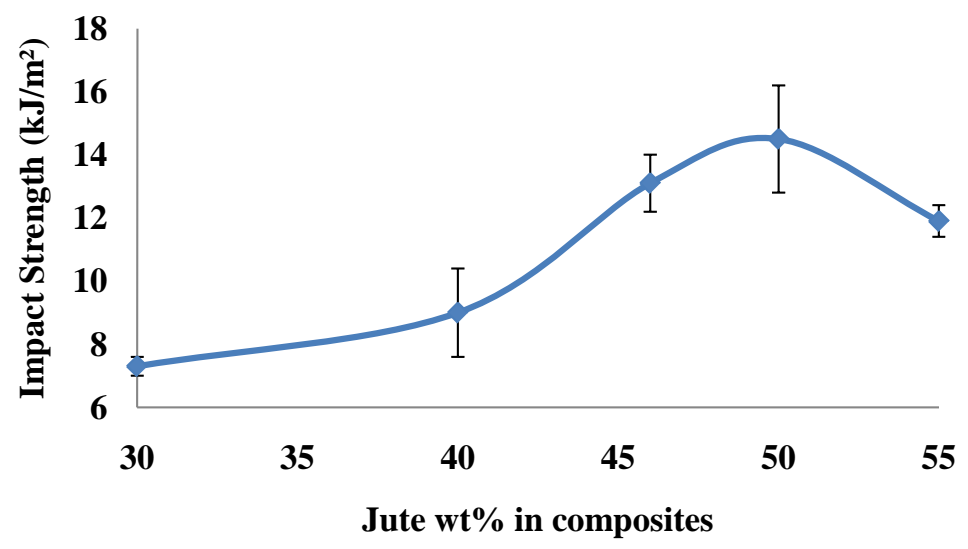

Figure 3. Effect of jute fiber loading (wt\%) on the IS of jute/PP composites.

fibers get agglomerated within the matrix which produces non-uniform stress transfer capacity. Also, too many fiber ends promote micro crack formation in the interface. As a result, strength and modulus of the composite again decrease [24] [25] [26] [27].

The impact strength (IS) of a material is its capacity to absorb and dissipate energies under impact or shock loading. IS of the composites were 7.3, 9.0, 13.1, 14.5 and $11.9 \mathrm{~kJ} / \mathrm{m}^{2}$ for the fiber content of $30 \%, 40 \%, 46 \%, 50 \%$ and $55 \%$ in the composites respectively as shown in Figure 3 and it was revealed that the IS increases with the increase in fiber content up to $50 \mathrm{wt} \%$ (96\% improvement than $30 \mathrm{wt} \%$ composite) and further it exhibited a declining trend upon fiber addition. It was evident that higher fiber loading increase the probability of fiber agglomeration and it's stress concentration requiring less energy for crack propagation. The maximum IS of the composite increase with fiber content up to $50 \mathrm{wt} \%$. Generally, the toughness of fiber reinforced polymer composites is dependent on the fiber, the polymer matrix and the interfacial bond strength [28] [29].

\subsection{Water Uptake (\%)}

Figure 4 shows the water uptake (\%) for jute/PP composite up to 168 hours. At 


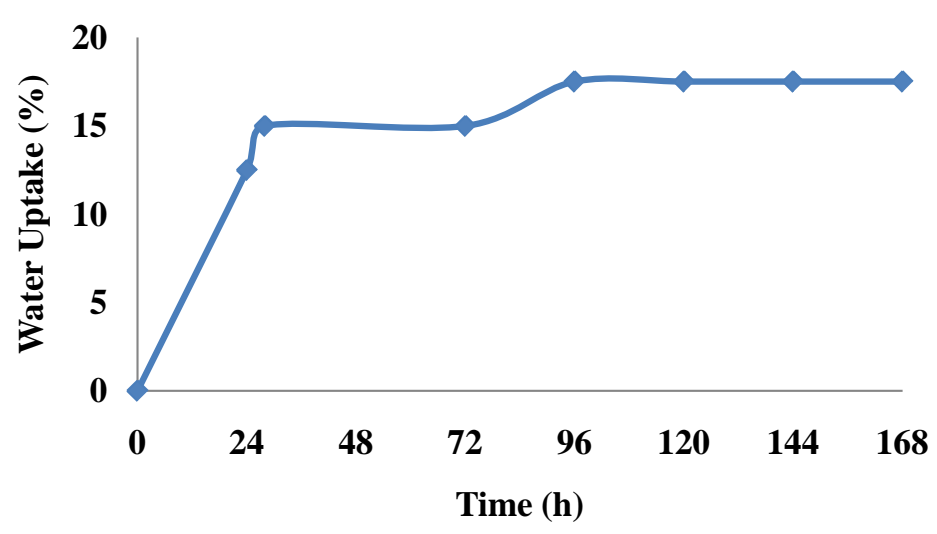

Figure 4. Water uptake (\%) of jute/PP composites.

first, the absorption rate was very high which was $12.5 \%$ for first 24 hour, then it steadily increased up to $17.5 \%$ till 96 hours and after 168 hours the absorption rate was same due to it reached into the saturation point.

Jute is basically made up of cellulose, which is a hydrophilic glucan polymer. The elementary unit of jute is anhydro-d-glucose, that carry 3 hydroxyl $(-\mathrm{OH})$ groups. The presence of these -OH groups in the cellulose structure is the main reason for the highly hydrophilic character of jute fiber. Hence, when immersed into water, jute absorbs huge amount of water within first hour [2] [6] [7].

\subsection{Chemical Ageing}

During various ageing period of $24,48,72,96,120,144,168$ hours, the weight gain were $17.5 \%, 17.5 \%, 20 \%, 20 \%, 20 \%, 17.5 \%$ and $15 \%$ respectively for $\mathrm{H}_{2} \mathrm{O}_{2}$ solution, $6 \%, 8 \%, 8 \%, 8 \%, 10 \%, 10 \%, 10 \%$ respectively for $\mathrm{NaOH}$ solution, $11.1 \%, 11.1 \%, 10 \%, 10 \%, 10 \%, 10 \%, 10 \%$ respectively for acid $(\mathrm{HCl})$ solution and $12.5 \%, 15 \%, 17.5 \%, 17.5 \%, 17.5 \%, 20 \%, 20 \%$ respectively for $\mathrm{NaCl}$ solutions as shown in Figure 5. After 24 hours the composite sample showed gradual absorption and then the weight gain was become slow and steady in the chemical media.

When the composite is immersed into the chemical solution such as acid, alkali or salt solution, the solution penetrates through the matrix and separates out in micro-cracks. On the other hand, the degradation of the fiber/matrix interface is caused by the dehydration of the matrix and penetration of solutions through micro-cracks, crazes or similar voids in the matrix [30] [31] [32]. For Hammami and Al-Ghilani [33] the degradation takes place via 2 stages. In the first stage, matrix is attacked under the combined action of water diffusion and the presence of $\mathrm{H}^{+}$. In the second stage the fiber itself is attacked and cracks appeared on the fiber surface. This affects significantly the composite resistance to loading stresses. The absorption of chemical solutions at various periods accelerated the rate of ageing. The outcome of this highly destructive process is evidenced by swelling, discoloration and decrease in the mechanical properties of the composites [34] [35] [36] [37]. 


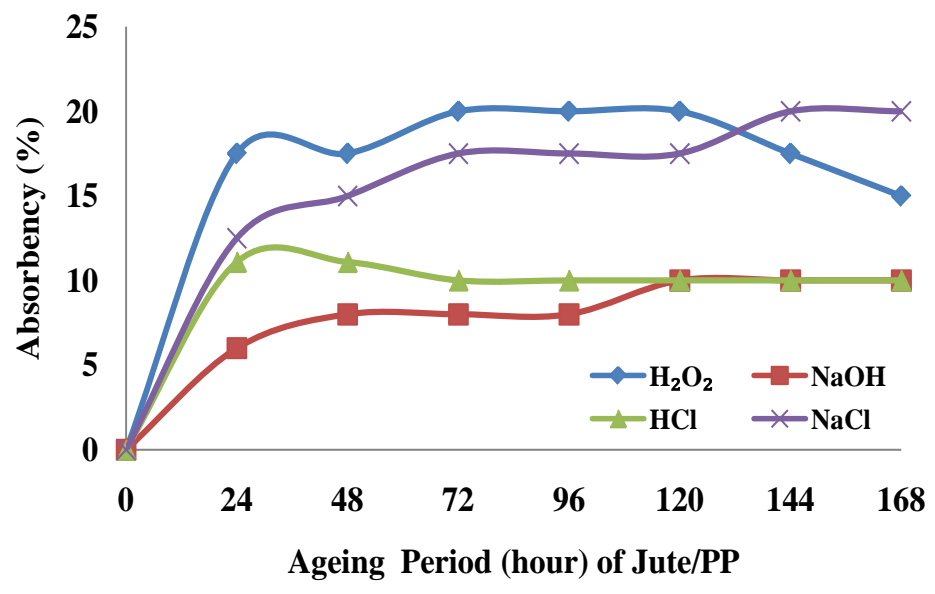

Figure 5. Chemical ageing of jute/PP composites.

\section{Conclusion}

Jute/polypropylene composites successfully fabricated with the increase of jute fiber loading by weight (\%). It was observed that by the addition of jute content in the composites, the mechanical properties were improved significantly and the maximum improvements were found for $50 \%$ jute fiber loading. The addition of fiber weight $\%$ on composites increased the mechanical properties up to $50 \%$ fiber but after that it showed a decreasing trend. Water absorption and weight gain in different chemical solutions such as alkali, acid and salt were revealed that initially the absorbency was very high and after that the absorption were steady and static with time. Finally, it can be concluded that fiber loading (\%) has significant influence on the mechanical properties of jute/polypropylene composites. The proper optimization of these processing parameters can be a better or viable solution of this composite for our domestic applications such as chair, table, fences, decking, bathtub etc.

\section{Acknowledgements}

The authors have been acknowledged to the Institute of Radiation and Polymer Technology (IRPT), Atomic Energy Research Establishment (AERE), Bangladesh Atomic Energy Commission, Savar, Dhaka for providing the laboratory facilities to complete this work.

\section{Conflicts of Interest}

The authors declare no conflicts of interest regarding the publication of this paper.

\section{References}

[1] Prashanth, S., Subbaya, K.M., Nithin, K. and Sachhidananda, S. (2017) Fiber Reinforced Composites-A Review. Journal of Material Sciences \& Engineering, 6, 341.

[2] John, M.J. and Thomas, S., (2008) Biofibres and Biocomposites. Carbohydrate Polymers, 71, 343-364. https://doi.org/10.1016/j.carbpol.2007.05.040 
[3] Gowda, T.G.Y., Sanjay, M.R., Bhat, K.S., Madhu, P., Senthamaraikannan, P. and Yogesha, B. (2018) Polymer Matrix-Natural Fiber Composites: An Overview. Cogent Engineering, 5, Article ID: 1446667.

[4] Pickering, K.L., Efendy, M.G.A. and Le, T.M. (2016) A Review of Recent Developments in Natural Fibre Composites and Their Mechanical Performance. Composites: Part A: Applied Science and Manufacturing, 83, 98-112. https://doi.org/10.1016/j.compositesa.2015.08.038

[5] Das, S.C. and Nizam, M.E.H. (2014) Applications of Fiber Reinforced Polymer Composites (FRP) in Civil Engineering. International Journal of Advanced Structures and Geotechnical Engineering, 3, 299-309.

[6] Akter, N., Saha, J., Das, S.C. and Khan, M.A. (2018) Effect of Bitumen Emulsion and Polyester Resin Mixture on the Physico-Mechanical and Degradable Properties of Jute Fabrics. Fibers, 6, 44. https://doi.org/10.3390/fib6030044

[7] Saha J., Das, S.C., Rahman, M., Siddiquee, M.A.B. and Khan, M.A. (2016) Influence of Polyester Resin Treatment on Jute Fabrics for Geotextile Applications. Journal of Textile Science and Technology, 2, 67-80. https://doi.org/10.4236/jtst.2016.24009

[8] Das, S.C., Paul, D., Fahad, M.M., Islam, T. and Nizam, M.E.H. (2017) Geotextiles-A Potential Technical Textile Product. Journal of Scientific and Engineering Research, 4, 337-350.

[9] Nizam, M.E.H. and Das, S.C. (2014) Geo Textile-A Tremendous Invention of Geo Technical Engineering. International Journal of Advanced Structures and Geotechnical Engineering, 3, 221-227.

[10] Das, S.C., Paul, D., Siddiquee, M.A.B., Islam, J.M.M. and Khan, M.A. (2016) Experimental Investigation and Analysis of Mechanical Behavior of Jute Fabric Reinforced Polyester Composites. Proceeding of the 2016 International Conference on Mechanical, Industrial \& Energy Engineering, Khulna, 26-27 December 2016, Paper ID: ICMIEE-PI-160-167.

[11] Khan, M.A., Khan, R.A., Haydaruzzaman, Hossain, A. and Khan, A.H. (2009) Effect of Gamma Radiation on the Physico-Mechanical and Electrical Properties of Jute Fiber-Reinforced Polypropylene Composites. Journal of Reinforced Plastics and Composites, 28, 1651. https://doi.org/10.1177/0731684408090365

[12] Haydaruzzaman, Khan, R.A., Khan, M.A., Khan, A.H. and Hossain, M.A. (2009) Effect of Gamma Radiation on the Performance of Jute Fabrics-Reinforced Polypropylene Composites. Radiation Physics and Chemistry, 78, 986-993. https://doi.org/10.1016/j.radphyschem.2009.06.011

[13] Haydaruzzaman, Khan, A.H., Hossain, M.A., Khan, M.A. and Khan, R.A. (2010) Mechanical Properties of the Coir Fiber-Reinforced Polypropylene Composites: Effect of the Incorporation of Jute Fiber. Journal of Composite Materials, 44, 401-416. https://doi.org/10.1177/0021998309344647

[14] Bakhori, S.N.M., Hassan, M.Z., Aziz, S.A., Fadzulah, S.H.S.M. and Ahmad, F. (2018) Tensile Properties of Jute-Polypropylene Composites. Chemical Engineering Transactions, 63, 727-732.

[15] Souzaa, B.R., Benedettoa, R.M.D., Hirayamaa, D., Raponia, O.A., Barbosaa, L.C.M. and Junior, A.C.A. (2017) Manufacturing and Characterization of Jute/PP Thermoplastic Commingled Composite. Materials Research, 20, 458-465. https://doi.org/10.1590/1980-5373-mr-2017-0104

[16] Haydaruzzaman, Khan, A.H., Hossain, M.A., Khan, M.A., Khan, R.A. and Hakim, M.A. (2010) Fabrication and Characterization of Jute Reinforced Polypropylene Composite: Effectiveness of Coupling Agents. Journal of Composite Materials, 44, 
1945-1963. https://doi.org/10.1177/0021998309356604

[17] Ramli, R., Yunus, R.M. and Beg, M.D.H. (2011) Effects of Fiber Loading, Fiber Type, Its Mesh Sizes, and Coupling Agent on the Properties of Oil Palm Biomass/Polypropylene Composites. Journal of Composite Materials, 45, 2165-2171. https://doi.org/10.1177/0021998311401069

[18] Rahman, M.R., Hasan, M., Huque, M.M. and Islam, M.N. (2010) Physico-Mechanical Properties of Jute Fiber Reinforced Polypropylene Composites. Journal of Reinforced Plastics and Composites, 29.

[19] Kasim, A.N., Selamat, M.Z., Aznan, N., Sahadan, S.N., Daud, M.A.M., Jumaidin, R. and Salleh, S. (2015) Effect of Pineapple Leaf Fiber Loading on the Mechanical Properties of Pineapple Leaf Finer-Polypropylene Composite. Jurnal Teknologi (Science and Engineering), 77, 117-123. https://doi.org/10.11113/jt.v77.6617

[20] Rasel, S.M., Nam, G.B., Byeon, J.M., Kim, B.S. and Song, J.I. (2011) Effect of Coupling Agent and Fiber Loading on Mechanical Behavior of Chopped Jute Fiber Reinforced Polypropylene Composites. Elastomers and Composites, 46, 204-210.

[21] Morii, T., Tomioka, S. and Hamada, H. (2011) Effect of Water Environment on Jute/Polypropylene Composites. Science and Engineering of Composite Materials, 18, 87-92. https://doi.org/10.1515/secm.2011.010

[22] Doan, T.T.L., Brodowsky, H. and Mader, E. (2007) Jute Fiber/Polypropylene Composites II. Thermal, Hydrothermal and Dynamic Mechanical Behavior. Composites Science and Technology, 67, 2707-2714. https://doi.org/10.1016/j.compscitech.2007.02.011

[23] Das, S.C., Paul, D., Siddiquee, M.A.B., Saha, J., Khan, M.A. and Islam, J.M.M. (2017) Study on the Mechanical Properties of Non-Woven Glass Fiber Reinforced Polyester Composites. Proceeding of the International Conference on Computer, Communication, Chemical, Materials and Electronic Engineering, Rajshahi, Paper No. 75 .

[24] Joseph, P.V., Joseph, K., Thomas, S., Pillai, C.K.S., Prasad, V.S., Groeninckx, G. and Sarkissova, M. (2003) The Thermal and Crystallization Studies of Short Sisal Fiber Reinforced Polypropylene Composite. Composite: Part A, 34, 253-266. https://doi.org/10.1016/S1359-835X(02)00185-9

[25] Mohanty, S. and Nayak, S.K. (2006) Interfacial Dynamic Mechanical and Thermal Fiber Reinforced Behavior of MAPE Treated Sisal Fiber Reinforced HDPE Composite. Journal of Applied Polymer Science, 102, 3306-3315. https://doi.org/10.1002/app.24799

[26] Das, S.C., Paul, D., Mamun, M.A.A, Mitro, B.K., Islam, M.T. and Khan, M.A. (2017) Synthesis and Experimental Investigation of PALF Twill Fabric Reinforced Polyester Biocomposites. Proceeding of the International Conference on Mechanical, Industrial and Materials Engineering, Rajshahi, Paper ID: MS-193, 82.

[27] Das, S.C., Islam, M.T., Khan, M.A., Mamun, M.A.A., Mittro, B.K., Saha, J. and Paul, D. (2017) Fabrication and Mechanical Characterization of PALF Plain Fabric Reinforced Polyester Biocomposites. Proceeding of the International Conference on Computer, Communication, Chemical, Materials and Electronic Engineering, Rajshahi, Paper No. 76, 55.

[28] Masud, S.H., Lawrence T.D. and Manjusri M. (2005) A Study on Biocomposites from Recycled Newspaper Fiber and Poly (Lactic Acid). Industrial \& Engineering Chemistry Research, 44, 5593-5601. https://doi.org/10.1021/ie0488849

[29] Islam, M.T., Das, S.C., Saha, J., Paul, D., Islam, M.T., Rahman, M. and Khan, M.A. (2017) Effect of Coconut Shell Powder as Filler on the Mechanical Properties of 
Coir-Polyester Composites. Chemicals and Materials Engineering, 5, 75-82.

[30] Kawada, H. and Srivastava, V.K. (2001) The Effect of an Acidic Stress Environment on the Stress Intensity Factor for GRP Laminates. Composites Science and Technology, 61, 1109-1114. https://doi.org/10.1016/S0266-3538(01)00008-2

[31] Stamenovic, M., Putic, S., Rakin, M., Medjo, B. and Cikara, D. (2011) Effect of Alkaline and Acid Solutions on the Tensile Properties of Glass-Polyester Pipes. Materials \& Desig, 32, 2456-2461. https://doi.org/10.1016/j.matdes.2010.11.023

[32] Stamenovic, M., Putic, S., Drmanic, S., Rakin, M. and Medjo, B. (2011) The Influence of Service Solutions on the Longitudinal and Circumferential Tensile Properties of Glass-Polyester Composite Pipes. Materials Science, 47, 61-69. https://doi.org/10.1007/s11003-011-9368-7

[33] Hammami, A. and Al-Ghuilani, N. (2004) Durability and Environmental Degradation of Glass Vinylester Composites. Polymer Composite, 16, 609-616. https://doi.org/10.1002/pc.20055

[34] Amaro, A.M., Reis, P.N.B., Neto, M.A. and Louro, C. (2013) Effects of Alkaline and Acid Solutions on Glass/Epoxy Composites. Polymer Degradation and Stability, $\mathbf{9 8}$, 853-862. https://doi.org/10.1016/j.polymdegradstab.2012.12.029

[35] Komai, K., Minoshima, K. and Shiroshita, S. (1991) Hygrothermal Degradation and Fracture Process of Advanced Fiber-Reinforced Plastics. Materials Science and Engineering A, 143, 155-166. https://doi.org/10.1016/0921-5093(91)90735-6

[36] Mahmoud, M.K. and Tantawi, S.H. (2003) Effect of Strong Acids on Mechanical Properties of Glass/Polyester GRP Pipe at Normal and High Temperatures. Polymer-Plastics Technology and Engineering, 42, 677-688. https://doi.org/10.1081/PPT-120023102

[37] Nakada, M. and Miyano, Y. (2009) Accelerated Testing for Long-Term Fatigue Strength of Various FRP Laminates for Marine Use. Composites Science and Technology, 69, 805-813. https://doi.org/10.1016/j.compscitech.2008.02.030 